\title{
A comparative diagnosis of students' proficiency in BIM in construction-related graduate programs in Brazil and in the United States
}

\section{SIGRADI2018 TECHNOPOLITICAS \\ xxii congresso da sociedade iberoamericana de gráfica digital 22th conference of the iberoamerican society of digital graphics 07|08|09|novembro|2018 iau usp | são carlos | sp br}

\author{
Aline Valverde Arrotéia \\ University of Sao Paulo | Brazil | aline.arroteia@usp.br \\ Daniel Paes \\ Georgia Institute of Technology | United States | dpaes3@gatech.edu \\ Javier Irizarry \\ Georgia Institute of Technology | United States | javier.irizarry@gatech.edu \\ Silvio Burrattino Melhado \\ University of Sao Paulo | Brazil | silvio.melhado@usp.br
}

\begin{abstract}
Although BIM has been transforming the AEC industry worldwide, the quality of BIM education is still unclear. In an effort to investigate the current state of BIM integration into higher education curricula, the main goal of this study was to evaluate, compare, and reflect on students' proficiency in BIM between two very distinct graduate courses in Brazil and in the United States. Findings suggest a critical lack of knowledge, either foundational (in the U.S.) or procedural knowledge (in Brazil). Finally, measures that could improve the students' proficiency in BIM are suggested.
\end{abstract}

Keywords: Building Information Modeling; Construction education; BIM proficiency; Collaborative environments.

\section{INTRODUCTION}

In the past recent years, the academic community has been searching for more effective teaching approaches that reflect the need for strong collaborative practices, as required by the increased level of design complexity, integrated delivery methods, and information modeling adoption in the construction industry. With the rapid development of economic globalization as well as science and technology, the scale of construction projects is increasing, the content and details of projects are more complex, and project schedules and quality requirements are more rigorous (Zhang et al., 2017). Consequently, today's professionals must be able to deal with complex projects that require multidisciplinary solutions (BecerikGerber, Gerber \& Ku, 2011).

Current construction-related graduate-level courses need to incorporate these collaborative solutions into their curricula and learning environments so that students are properly prepared to respond to the industry's demands. Since mid-2000s, new proposals have been implemented in order to improve student's learning of Building Information Modeling and related collaborative practices; including both conceptual and procedural knowledge.

Although the issue of BIM in the Architectural, Engineering and Construction (AEC) education has attracted much attention in academic literature, little is known about what the current status of BIM is in the AEC curricula (BecerikGerber, Gerber \& Ku, 2011). Moreover, the extent of adoption and effectiveness of these initiatives are also still unclear.

In this context, the main objective of this study is to investigate, compare, and reflect on the current level of BIM knowledge of students from two graduate-level courses in different countries, Brazil and United States. In Brazil, the study was conducted with the participation of students of a course named Building Information Modeling from the Architecture and Urbanism standpoint, within the Architecture School graduate program of University X. In the U.S., participants were students of a course named Technology Applications in the Construction Industry, within the School of Building Construction of University Y.

\section{LITERATURE REVIEW}

\section{BIM IN AEC INDUSTRY}

The adoption of Building Information Modeling (BIM) represents a paradigm shift in the AEC industry. BIM is considered as an innovative and efficient technology, fostering more collaborative approaches to the building life cycle, adding digital parametric elements with information from early design and construction phases, up to maintenance and demolition stages (Donato, Lo Turco \& Bocconcino, 2017).

BIM can be applied into large and complex projects where its ability to link construction information to a visually rich three-dimensional representation (3D model) helps to 
resolve design, cost, time and constructability issues in an integrated fashion (McGraw Hill Construction, 2014). Succar (2009) states that BIM is a useful tool for reducing the construction industry's fragmentation. The use of BIM applications can benefit design, construction and facilities management (Eastman et al., 2011). Due to its benefits, BIM has become a reality worldwide (Eastman et al., 2011; Puolitaival, Forsythe, 2016). As per Lu et al. (2013), BIM has transformed the traditional AEC practices in a broad sense - in terms of people, processes, working culture, communication, and business models. However, the lack of adequately BIM trained personnel is still a significant constraint hindering a potentially wider adoption of the technology in the industry (Becerik-Gerber, Gerber \& Ku, 2011).

\section{BIM IN ACADEMIA}

The construction industry is moving towards more collaborative practices worldwide, aided by BIM tools and processes. However, higher education is lagging behind. Just as industry is undergoing a paradigm shift, from its old culture of fragmentation to one of integration and information sharing, so must academia (MacDonald, 2012).

To provide students with BIM skills as required by the current construction industry, many construction education institutions are introducing BIM in their coursework and hiring new faculty based on their expertise in BIM (Joannides, Olbina \& Issa, 2012). Also, many schools now realize the potential of BIM applications as powerful teaching tools that help instructors to engage students with the class content, improving their learning experiences. Adopting and teaching BIM from the early stages of undergraduate education can provide future professionals with more experience with the technology (Irizarry et al., 2013).

Nonetheless, a study conducted at the University of Liverpool found that BIM adoption in the academic environment has been challenging. Although the British construction industry has shown successful experiences, the main obstacles towards the integration of BIM into UK curricula and teaching environments are the highly creative aspect of the architecture practice, and the difficulties inherent to fostering collaboration among disciplines (Kocaturk, Kiviniemi, 2013). Barison and Santos (2011) found that only $7 \%$ of the universities surveyed adopt collaborative and interdisciplinary BIM teaching practices, whereas the vast majority of the surveyed programs (90\%) teach BIM within one course only.

Becerik-Gerber, Gerber \& Ku (2011) developed a thorough study on the current state of BIM within the AEC higher education in the U.S. The study found that the level of BIM integration into the North American curricula is higher in architecture programs, as opposed to in engineering programs and construction management programs. Overall, $56 \%$ of all programs offer BIM courses. The majority of these programs (88\%) are undergraduate programs.

In summary, the adoption of BIM towards collaborative learning environments has been little practiced by academic institutions as opposed to the many initiatives already implemented across the industry (MacDonald; Mills, 2013).

\section{METHODOLOGY}

The research method consists of a qualitative, comparative case study. Yin (2005) defines case study as a method of empirical research, which seeks to investigate a phenomenon within the context of real life. A case study is characterized by being a detailed study that aims at producing broad and deep knowledge on one or a few objects (Gil, 2002).

In this case study, data collection was conducted using online surveys, semi-structured interviews and participatory evaluation. The nonrandom convenient sampling process consisted of inviting students through emails and face-to-face invitations. Participants were informed that their participation was voluntary and anonymous, and had absolutely no impact on the evaluation of their academic performances. Data analysis is qualitative and made upon the interpretation of participants' subjective answers.

\section{DATA COLLETION}

This study involved the utilization of an online survey form comprising close- and open-ended questions, including demographics, and semi-structured in person interviews with the support of an interview guide/script - as instruments for data collection. The online survey was developed with Google Forms web-based application and distributed to all participants. They were asked to take the survey at any time prior to their interview meeting with the $\mathrm{PhD}$ research assistant. The online form consisted of twenty-four questions in total - demographics included. Interviews were conducted in person and took approximately ten minutes per participant, who were asked a total of eight questions.

In addition, all interviews were recorded in audio so that responses could be transcribed and better analyzed later on. All students answered the very same questions, either of the online form or during interviews. Data collection was performed in Brazil during Fall semester of 2016 (AugustDecember), and during Spring semester of 2018 (JanuaryMay) in the U.S.

\section{RESULTS}

\section{SURVEY}

The sample size is of twenty participants in total $(\mathrm{N}=20)$. Eleven participants are graduate students in Brazil, whereas nine are graduate students in the United States. The demographics of the sample are provided in Table 1 below.

Table 1: Sample demographics.

\begin{tabular}{|c|l|c|c|}
\hline \multicolumn{2}{|c|}{ Attribute } & U.S., N=9 & BRA, N=11 \\
\hline \multirow{2}{*}{ Age range } & $20-30$ & $89 \%$ & $18 \%$ \\
\cline { 2 - 4 } & Over 30 & $11 \%$ & $82 \%$ \\
\hline \multirow{2}{*}{ Gender } & Male & $67 \%$ & $36 \%$ \\
\cline { 2 - 4 } & Female & $33 \%$ & $64 \%$ \\
\hline \multirow{2}{*}{$\begin{array}{c}\text { Graduation } \\
\text { year }\end{array}$} & Before 2010 & $11 \%$ & $55 \%$ \\
\cline { 2 - 4 } $\begin{array}{c}\text { Educational } \\
\text { level }\end{array}$ & After 2010 & $89 \%$ & $45 \%$ \\
\cline { 2 - 4 } Profession & Master std. & $100 \%$ & $82 \%$ \\
\hline \multirow{2}{*}{\begin{tabular}{c} 
Poctoral std. \\
\cline { 2 - 4 }
\end{tabular}} & Architect & $0 \%$ & $18 \%$ \\
\cline { 2 - 4 } & Civil Engineer & $33 \%$ & $82 \%$ \\
\cline { 2 - 4 } & Other & $56 \%$ & $0 \%$ \\
\hline
\end{tabular}


Along with the interviews, the online survey provided valuable data on the students' proficiency in BIM. Main results are described in the charts below (Figures 1-6). Short comments are draw on the information the charts provide added by data collected from the other survey questions.

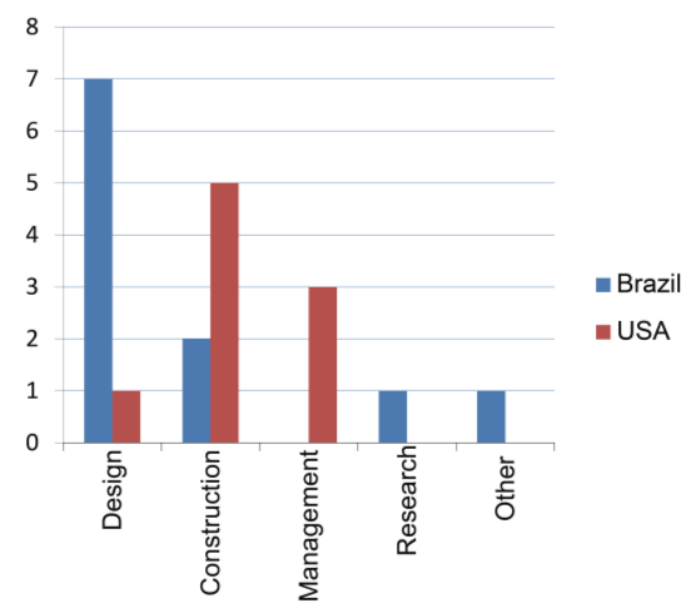

Figure 1: Field of professional practice. Source: Authors.

In regards to the participants' field of professional practice, most Brazilian graduate students are or were involved with building design, whereas North American students work or have worked with construction or construction management. Half the North American students have up to 1 year of practice, and half between 1-5 years. On the other hand, more than half the Brazilian students have over 5 years of professional experience.

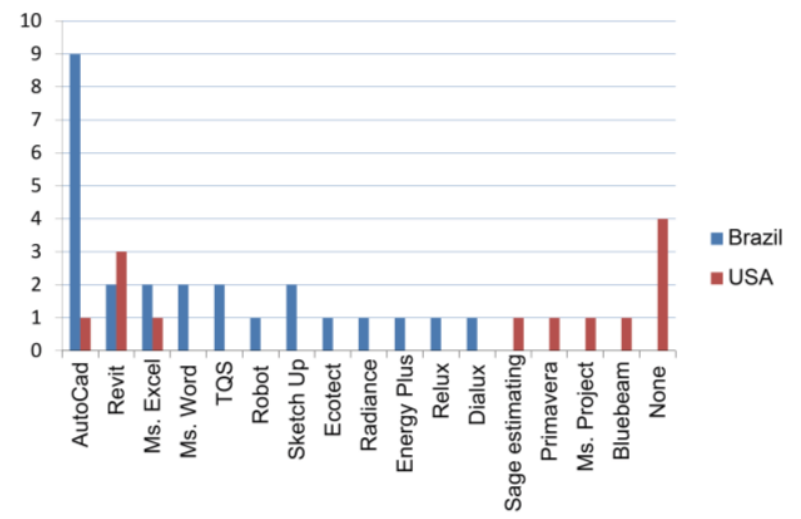

Figure 2: Software applications used. Source: Authors.

In regards to software applications used, AutoCAD is the most utilized tool by Brazilian students (among many others). Virtually all these students are currently involved with building design. On the contrary, nearly all North American students do not currently work with design. The most adopted computational tools among these students include a variety of construction management applications and Revit (these students are more involved with construction or construction management).

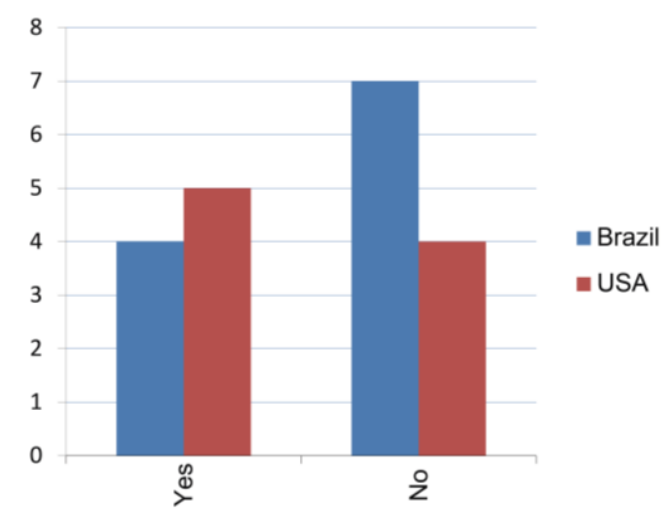

Figure 3: Use of BIM applications. Source: Authors.

In regards to use of BIM applications specifically, most U.S. graduate students work or have worked with BIM tools, whereas most Brazilians have not. Students who have worked with BIM (both North Americans and Brazilians) have done it for less than one year.

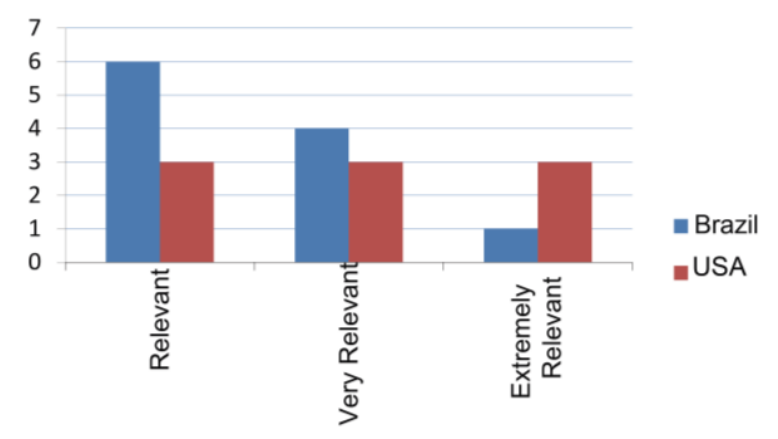

Figure 4: Course relevance to field of study. Source: Authors.

In regards to the participants' perception on the course relevance to their field of study - while being graduate students - the Brazilian students rated the course as relevant or very relevant, whereas the North American students are evenly distributed among relevant, very relevant and extremely relevant.

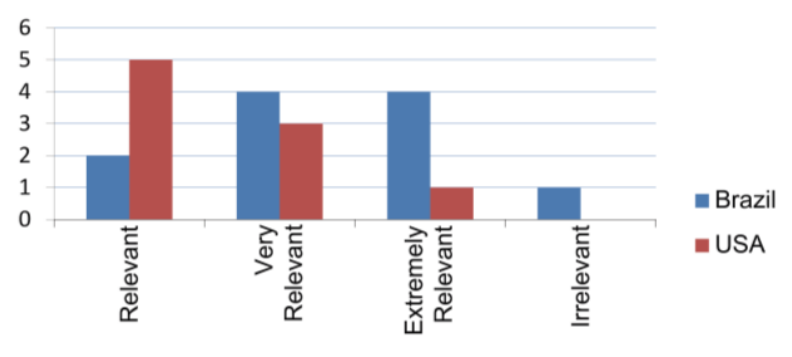

Figure 5: Course relevance to professional practice. Source: Authors.

In regards to the participants' perception on the course relevance to professional practice, most Brazilian students rated the course as very or extremely relevant, whereas most North American students rated it as relevant or very relevant. 


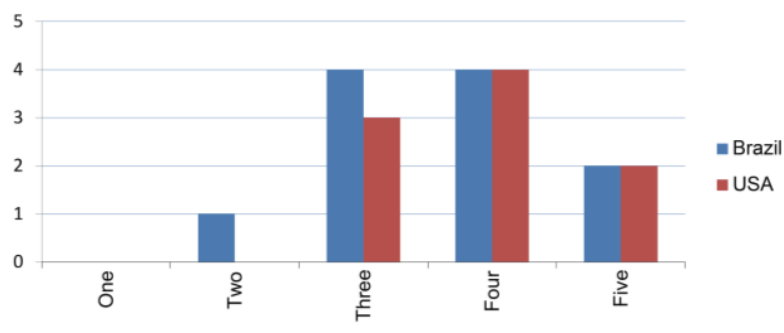

Figure 6: Knowledge about BIM after course. Source: Authors.

In regards to the participants' knowledge about BIM after attending the course, which reflects their final proficiency, most Brazilian students rated it as 3 or 4 , on a scale ranging from 1 to 5 . Similarly, most North American students rated their knowledge as 3 or 4 .

\section{SEMI-STRUCTURED INTERVIEWS}

Semi-structured interviews were conducted with seven out of the eleven Brazilian students of the survey sample, and with all nine North American students. A summary of the students' answers is provided next.

\section{Question 1: What is your area of expertise?}

Brazil: The majority of students were architects working as designers or consultants. Only one student was a civil engineer.

USA: Most students are civil engineers and working with building construction or construction management.

Question 2: Do you work with design development? If yes, of which building typologies?

Brazil: Six students answered that they have been working with the development of architectural design. In regards to building typologies, the answers involved a variety of typologies such as residential, hospitals, schools, industrial, institutional, urbanism, and others.

USA: Most answers were negative. Most students have been worked with infrastructure, not design. Only two students answered that they used to work with 3D models of residential typologies.

Question 3: Do you use any BIM applications for design development? If yes, which one(s)? If no, which other applications do you use?

Brazil: Five students stated that they have not used any BIM applications so far. Instead, they have been using AutoCAD for design development. Two students stated that they work with BIM.

USA: In general, the answers were negative. Most students have never used BIM. Usually, they work with other applications such as AutoCAD. Two students answered that they work with BIM.

\section{Question 4: How long have you known BIM?}

Brazil: Most students answered that they first heard about BIM around 8 to 10 years ago. Only two students stated that they have known BIM for 3 years.
USA: Four students answered that they got to know BIM at the beginning of the course semester. Four students stated that they have known BIM for 3 years. Only one student confirmed to know BIM for 10 years.

Question 5: Which software applications have you been used before you get to know BIM?

Brazil: All answers were AutoCAD. Some students stated that they also have used SketchUp and 3dsMax.

USA: Half the students stated that they used to work with AutoCAD before BIM. One student reported that he used to work with Bluebeam. The other half stated that they did not use any applications.

Question 6: In your opinion, can BIM enhance the design process?

Brazil: Four answers were negative (these students have never used BIM before). The others answered positively in regards to BIM benefits to the design process.

USA: All answers were positive: "With a BIM model, all stakeholders share the same idea and information"; "BIM helps clash detection, planning, and promotes more collaboration among disciplines"; "BIM allows for design visualization and stakeholders involvement".

\section{Question 7: Do you believe that the design process changes with BIM adoption? If yes, how?}

Brazil: All students responded positively. In general, they stated that BIM could be helpful if implemented in a collaborative fashion; it would be necessary to plan ahead all the steps for implementation.

USA: All answers were positive as well. The students stated that "BIM makes the design process easier and faster"; "BIM gives a good sense of space"; "With BIM, we can see all changes easily".

\section{Question 8: In your opinion, what are the positive and negative aspects in regards to BIM adoption?}

Brazil: Positive aspects: "More integration between design and construction phases"; "Better design visualization"; "Simulation"; "Better information sharing and collaboration among stakeholders"; "Facility management control". Negative aspects: "Hard to find trained professionals to work with"; "Different interfaces across software applications"; "Lack of knowledge"; "Costs and time for implementation", "Difficulties associated to learning a new design process".

USA: Positive aspects: "Better design process"; "Design is more clear"; "Gives more options to the client"; "Brings more quality, faster process"; "Integrates different players in early design"; "Constructability and collaboration". Negative aspects: "Time-consuming training"; "Forces you to not be creative", "Makes it more expensive to hire people", "The main challenge is to make everybody work together", "Lots of software applications". 


\section{DISCUSSION}

As described in the previous section, the study results indicate a significant profile disparity between Brazilian and North American graduate students who made up the study sample. In general, Brazilian graduate students are older, mostly architects involved with design, and with notably more professional experience, as opposed to North American students who, in general, have graduated from college after 2010, are neither architects nor civil engineers, and mostly involved with construction or construction management. The reasons that lead the participating graduate programs to have such different student bodies are more complex than this study can explain; it may involve societal, cultural and economical aspects.

As expected from such sample distribution and study timeframe, Brazilian students - who are mostly involved with building design - work or have worked with AutoCAD, whereas most North American students, although not designers and not familiar with AutoCAD, have had some experience with BIM software. Because U.S. graduate students are younger and have graduated from college more recently, this finding may reflect the increase of BIM adoption by the U.S. construction industry in the past few years, that is, new generations may be experiencing that paradigm shift already. In this sense, North American students may be slightly more proficient in BIM, due to the fact that they have had some contact with it.

North American students, in general, consider BIM as slightly more important to their field of study than Brazilians do. However, when it comes to the importance of learning BIM to their professional practice, Brazilian students may perceive it as more important than North Americans do. That is, Brazilians may better perceive or may be more aware of the benefits of BIM to the professional practice, and by doing so, prove to be more proficient in BIM in this sense.

At this point, there seems to be a slight discrepancy between how Brazilians and North American students understand the importance of BIM-based tools and processes. While North Americans may have more technical/procedural knowledge on how to operate BIM tools, Brazilian students may better understand conceptually - the implications, challenges and benefits of BIM adoption. Perhaps not by coincidence, the groups rated themselves as equally proficient (Figure 6). In summary, their level of proficiency may be equivalent, but they realize BIM in different ways.

In general, results suggest a critical lack of knowledge in both groups of students, which yields the need for a thorough review of both graduate programs' curricula. The North American graduate program may need to counterbalance its curricula by adding more theoretical and foundational knowledge content, prompting students to reflect on why, how and when to use BIM so that they better realize the transformative potential of this technology. On the other hand, the Brazilian graduate program might consider introducing hands-on activities into the curricula, allowing students to get familiar with the operation and capabilities of BIM tools so that they are able to respond to the industry's current demand for well-trained and qualified BIM professionals.

\section{CONCLUSIONS}

This article described a short, comparative, qualitative study on students' proficiency in BIM in constructionrelated graduate programs in Brazil and in the United States, and concluded that their level of proficiency is similarly lacking, and that students realize BIM in different ways. The study looked at students' knowledge about BIM in two very distinct graduate courses, aiming at developing an unbiased comparative analysis about how BIM is integrated into the curricula of higher education institutions that differ on social, cultural and economical aspects. The assessment revealed a critical lack of knowledge among the students, either foundational (in the U.S.) or procedural knowledge (in Brazil). In light of previous studies and industry's current demands, the study recommends corrective measures that could leverage the integration of BIM into both programs' curricula and improve students' proficiency in BIM.

This research represents a contribution to the debate on the current state of BIM proficiency within the AEC higher education worldwide, more specifically, on the extent of adoption and effectiveness of BIM teaching practices. As a result, it provides insights to current and future construction-related graduate programs that aim to contribute to the training and education of future BIM professionals. Since it is critical to have a clear up-to-date picture of how higher education institutions are doing in BIM training, future works may perform similar studies involving larger samples, different countries, and other proficiency indicators.

\section{ACKNOWLEDGMENTS}

This study was financed in part by the Coordenação de Aperfeiçoamento de Pessoal de Nível Superior - Brasil (CAPES) - Finance Code 001.

\section{REFERENCES}

Becerik-Gerber, B., Gerber, D. J., Ku, K. (2011). The pace of technological innovation in architecture, engineering, and construction education: integrating recent trends into the curricula. Journal of Information Technology in Construction (ITcon), 16, 411-432.

Barison, M. B., Santos, E. T. (2011). Ensino de BIM: Tendências atuais no cenário internacional. Revista Gestão \& Tecnologia de Projetos, 6(2),67-80.

Donato, V., Lo Turco, M., Bocconcino, M. M. (2017). BIM-QA/QC in the architectural design process. Architectural Engineering and Design Management, 1-16. doi: 10.1080/17452007.2017.1370995

Eastman, C. M., Teicholz, P., Sacks, R., and Liston, K. (2011). BIM handbook: A guide to building information modeling of owners, managers, designers, engineers and contractors, Hoboken, NJ: John Wiley and Sons.

Gil, A.C.(2002) Como Elaborar Projetos de Pesquisa. 4ª ed. São Paulo, SP: Atlas.

Irizarry, J. et al. (2013) Human computer interaction modes for construction education applications: experimenting with small format interactive displays. International Journal of Construction Education and Research, 9(2), 83-101.

Joannides M. M., Olbina, S., Issa, R. R. A. Implementation of Building Information Modeling into Accredited Programs in Architecture and Construction Education, International Journal of Construction Education and Research, 8:2, 83-100, doi: 10.1080/15578771.2011.632809. 
Kocaturk, T.; Kiviniemi, A. "Challenges of integrating BIM in Architectural Education. In: COMPUTATION AND PERFORMANCE - 31ST INTERNACIONAL CONFERENCE ON EDUCATION AND RESEARCH IN COMPUTER AIDED ARCHITECTURAL DESIGN IN EUROPE - ECAADE. Delft, Proceedings... Delft: Delft University of Technology, Faculty of Architecture, 2013. 9. Liverpool, United Kingdom.

Lu at al. (2013). Generic Model for Measuring Benefits of BIM as a Learning Tool in Construction Tasks. Journal of Construction Engineering and Management, 139 (2), 195-203.

MacDonald, J. A. (2012). A framework for collaborative BIM education across the AEC disciplines. In: 37th ANNUAL CONFERENCE OF AUSTRALASIAN UNIVERSITY BUILDING EDUCATORS ASSOCIATION. 2012, Sidney. Proceedings... Sidney: AUBEA, 2012. 11. Sidney, Australia.

MacDonald, J. A.; Mills, J. (2013) 'An IPD approach to construction education. Australasian Journal of Construction Economics and Building, 13 (2), 93-103.
McGraw Hill Construction (2014). The Business value of BIM for construction in major global markets. How contractors around the world are driving innovation with Building Information Modeling, Smart Market Report, McGraw Hill Construction Research \& Analytics, Bedford, MA.

Puolitaival, T., Forsythe, P. (2016). Practical challenges of BIM education. Structural Survey, 34(4/5), 351-366.

Succar, B. (2009). Building information modeling framework: A research and delivery foundation for industry stakeholders. Automation in Construction, 18(3), 357-375.

Zhang et al. (2017). BIM-Based Collaboration Platform for the Management of EPC Projects in Hydropower Engineering. J. of Constr. Eng. Manage. 143 (12), 04017087-1-15.

Yin, R.K. (2005). Estudo de caso: planejamento e métodos. Porto Alegre.RS:Bookman. 